\title{
EDUCAÇÃO AMBIENTAL NO COTIDIANO ESCOLAR
}

Lucas Alves Emanoel Efísio - lucas.efisio@gmail.com

Universidade Federal de Juiz de Fora (UFJF)

Patrícia Dias Vieira - pdiasvieira@gmail.com

Universidade Federal de Juiz de Fora (UFJF)

Caroline Bordim Ladeira - caroline.ladeira@engenharia.ufjf.br

Universidade Federal de Juiz de Fora (UFJF)

Fernanda Raphaela Pantojo de Souza - fernanda.pantojo@engenharia.ufjf.br

Universidade Federal de Juiz de Fora (UFJF)

Marconi Fonseca de Moraes - moraescmf@gmail.com

Universidade Federal de Juiz de Fora (UFJF)

Luana Ribeiro de Oliveira - luana.ribeiro@engenharia.ufjf.br

Universidade Federal de Juiz de Fora (UFJF)

Gabriela David Vázquez - gabriela.vazquez@engenharia.ufjf.br

Universidade Federal de Juiz de Fora (UFJF)

Ilva Maria Gomes Rodrigues - moraescmf@gmail.com

Escola Estadual Batista de Oliveira

Maristela Lomar da Silva - moraescmf@ gmail.com

Escola Municipal Theodoro Frederico Mussel 


\section{RESUMO}

Nos dias atuais, a sociedade vem enfrentando cada vez mais problemas ambientais, tais como acúmulo de resíduos sólidos, poluição do ar e contaminação dos recursos hídricos superficiais e subterrâneos. Grande parte desses problemas enfrentados pela sociedade são causados por atividades antrópicas, decorrentes tanto de uma falta de conhecimento acerca da dinâmica da natureza e dos seres vivos, quanto da adoção de hábitos ecologicamente inadequados. Com isso, criou-se a necessidade de se trabalhar a educação ambiental, com vistas à minimização dos problemas ambientais através de ações educativas que visam à mudança de comportamento. A educação ambiental desempenha um importante papel na formação social do indivíduo, uma vez que fornece subsídios para a sadia relação entre os homens e, também, entre o homem e a natureza. Tendo em vista essa importância, o presente trabalho busca mostrar as atividades desenvolvidas nas instituições de ensino: Escola Municipal Theodoro Frederico Mussel e Escola Estadual Batista de Oliveira, situadas na cidade de Juiz de Fora, Minas Gerais - Brasil, a fim de aplicar os conceitos da Educação Ambiental em seu cotidiano. Para tal, foram utilizados recursos pedagógicos, como palestras (consumo consciente de energia elétrica, Dengue, chikungunya, Zika vírus, ITS...), oficinas (fabricação de repelente caseiro, sabão ecológico...), jogos educativos (jogo de tabuleiro sobre a transmissão e prevenção da Dengue) e outras atividades em grupo que estimulam o senso crítico, respeitando a faixa etária dos alunos atendidos. Durante todo o projeto, apresentou-se propostas de mudanças de hábitos para crianças e adolescentes e incentivou-se que os mesmos pudessem repassar o aprendizado recebido para toda a família e comunidade.

Palavras-chave: Escola, Educação, Sustentabilidade. 


\section{INTRODUÇÃO}

A história de vida de uma pessoa começa antes do seu nascimento e vai se processando ao longo do tempo. Enquanto o primeiro nascimento do ser humano corresponde ao seu nascimento real, ao nascer para a família e para a espécie, o segundo ocorre na adolescência, ao nascer para si mesmo e para a sociedade (SERRÃO; BALEEIRO, 1999). E este período, de acordo com a Organização Mundial de Saúde (Friedman, 1985), vai dos dez e aos dezenove anos.

Os jovens vão substituindo o amor incondicional, a fé e a inocência típicas da fase infantil pela participação em grupo, por um ideal, uma meta. Ou seja, conforme Serrão e Baleeiro (1999), adolescer, não representa apenas um momento de crise, mas também o momento em que as escolhas serão realizadas e projetos começarão a ser construídos.

É também nessa fase que estão mais expostos a fatores de risco, tais como: dificuldades na aprendizagem ou evasão escolar, sexo sem proteção, gravidez, paternidade ou maternidade adolescentes, delinquência, violência e criminalidade.

Um tema essencial na formulação do projeto "Minha Escola Minha Vida" é a questão do trabalho. Discutir trabalho indo além da escolha profissional e da obtenção de um emprego. Ou seja, abrir espaço para que o adolescente se expresse sobre o tema suas inquietações, temores, anseios, expectativas; possibilitando-lhe perceber o trabalho como realização pessoal e meio de participação na transformação do mundo frente às questões ambientais.

\section{METODOLOGIA}

Para fins de execução do projeto de Educação Ambiental, foi firmada uma parceria com as Escolas: Escola Municipal Theodoro Frederico Mussel e Escola Estadual Batista de Oliveira, no município de Juiz de Fora, Minas Gerais - Brasil.

O projeto funciona da seguinte forma: a coordenação da escola disponibiliza a temática de acordo com sua necessidade e datas comemorativas e os alunos da Universidade Federal de Juiz de Fora apresentam propostas que se adequem ao tema e ao objetivo do trabalho realizado pela mesma. As atividades também podem ser propostas pelos professores e os graduandos participam da execução do projeto. Os temas são estabelecidos de acordo com um calendário semestral e os mesmos são 
desenvolvidos, ao menos, uma vez ao mês, procurando executar os mesmos temas em ambas escolas.

Devido ao grande número de casos de dengue, febre pelo vírus Zika e febre Chikungunya, registrados na cidade de Juiz de Fora, esse tema foi o escolhido para ser trabalhado no mês de março de 2016. Segundo informações do Ministério da Saúde, foram registrados no país 495.266 casos prováveis de dengue apenas no período de 03/01/2016 a 05/03/2016, sendo a maioria deles (56,6\%) na região Sudeste. Diante deste cenário, é de fundamental importância que o tema seja trabalhado nas escolas, onde os alunos podem se informar a respeito dos mecanismos de transmissão e prevenção da doença.

No mês de abril, no dia 18, comemora-se o Dia Nacional do Livro Infantil. Foi realizada uma tarde de leitura com os alunos, com idades entre 4 e 6 anos. Por meio da leitura, a criança estimula sua criatividade e adquire conhecimentos importantes para a sua vida. Mesmo crianças de faixas etárias mais baixas podem se beneficiar da familiaridade com o mundo da leitura, já que ela serve de suporte para o aprendizado e pode ajudar no processo de alfabetização.

No mês de maio, devido ao Dia do Trabalhador, comemorado no dia 01, foi realizada uma feira de profissões com os alunos do Ensino Médio. O trabalho é uma parte primordial da vida em sociedade. Contudo, muitos alunos podem se sentir receosos quanto a este tema, que vai muito além de se escolher uma profissão. Então, é foco da educação ambiental guiá-los nesse caminho, apresentando-lhes opções e buscando reduzir os anseios dos jovens quanto a questões profissionais.

No dia 05 de junho é comemorado o Dia Mundial do Meio Ambiente. Em virtude disso, a fim de mostrar técnicas ambiental e economicamente sustentáveis, desenvolveu-se uma oficina sobre tinta ecológica com os alunos do quarto ano (idades entre 9 e 10 anos).

A partir do mês de agosto, trabalhou-se no desenvolvimento de um Workshop que visava a educação ambiental dos professores, para posterior trabalho com os alunos. Este Workshop foi realizado no mês de outubro.

Em 01 de dezembro, devido ao Dia Mundial de Combate à AIDS, foi realizado um dia de palestra sobre Infecções Transmitidas sexualmente, para conscientizá-los sobre a importância do assunto. 
É importante salientar que as atividades foram feitas em concordância com o corpo docente das escolas, para que tomassem conhecimento do planejamento e oferecessem suas próprias sugestões, a fim de que não houvesse interferências na agenda pedagógica da escola.

\section{RESULTADOS E DISCUSSÕES}

As atividades desempenhadas pelos bolsistas nas escolas são detalhadas nos parágrafos seguintes.

\subsection{Atividades sobre a Dengue}

No dia 01 de março, as atividades foram feitas com os alunos do $4^{\circ}$ e $5^{\circ}$ ano do Ensino Fundamental, com faixa etária entre 9 e 10 anos de idade.

Em um primeiro momento, foi feita a apresentação da equipe de trabalho aos alunos (graduandos e o professor universitário) e, em seguida, foi feita uma rápida introdução ao tema dengue, com o objetivo de se aferir o nível de conhecimento dos alunos acerca da doença e de sanar as eventuais dúvidas que os alunos pudessem ter a esse respeito.

Depois disso, foi dado início às atividades programadas: um jogo educativo, confecção de uma armadilha para os mosquitos Aedes Aegypti e a demonstração de uma receita de repelente caseiro.

\subsubsection{Jogo educativo}

Os bolsistas confeccionaram em casa cinco jogos de um tabuleiro educativo (modelo sobre a dengue oferecido pela Prefeitura de Juiz de Fora para uso acadêmico), que consistia em um tabuleiro de cartolina, um dado e quatro ou cinco peões feitos com tampinha de garrafa pet e adesivos para diferenciar (a quantidade de peões foi adaptada no momento do jogo, de acordo com a quantidade de alunos em cada grupo). No tabuleiro, as casas continham frases de conscientização sobre o mosquito Aedes Aegypti, os sintomas da dengue e medidas de combate da doença, como não deixar água parada, preencher o pratinho dos vasos de plantas com areia, entre outros. Continham também instruções de seguir ou regressar determinado número de casas. 
Após as instruções iniciais, os alunos foram separados em cinco grupos de quatro ou cinco pessoas. Foi pedido a cada aluno que lesse em voz alta a frase da casa correspondente ao número tirado no dado.

A foto 1, mostra um grupo de alunos durante o jogo de tabuleiro.

Foto 1 - Alunos durante o jogo de tabuleiro

Fonte: Acervo próprio

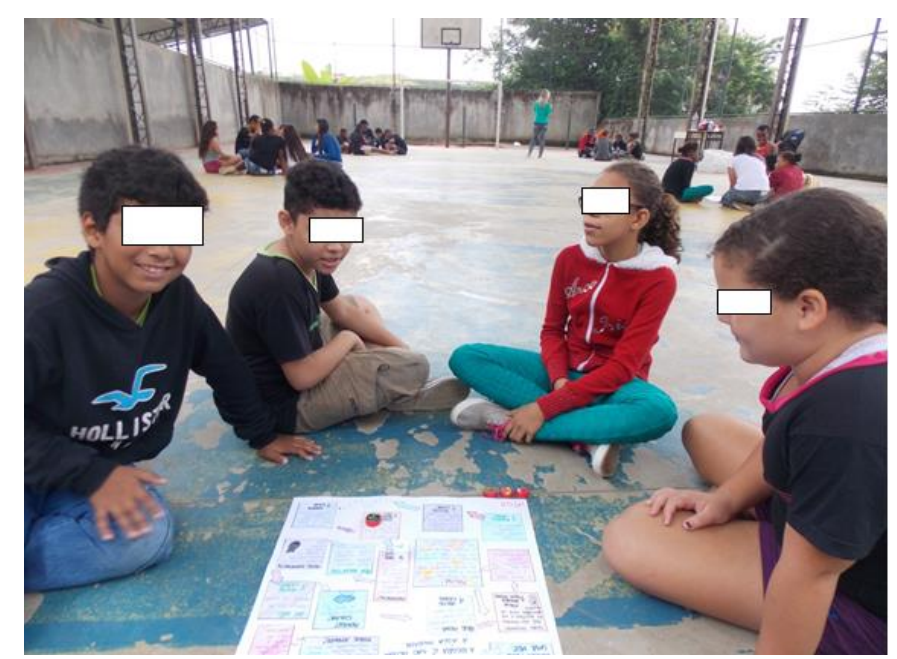

Ao final se seguiu uma conversa informal e perguntou-se quais informações tinham sido absorvidas do jogo, a fim de fixá-las.

\subsubsection{Armadilha para o mosquito Aedes aegypti}

Foi confeccionado uma armadilha para mosquitos Aedes aegypti junto com os alunos, seguindo um modelo tirado da internet, e utilizando garrafa pet, fita isolante, um pedaço de tecido de mosquiteiro ou tule e ração para gatos.

Para a construção da armadilha corta-se uma garrafa grande ao meio e tira-se o anel plástico da boca da garrafa, sem rompê-lo; ali coloca-se um pedaço de tule e voltase a encaixar o anel, de modo a prender o tecido. Dentro da garrafa coloca-se poucos grãos de ração e logo é encaixado a parte de cima, que se assemelha a um funil, agora virada para baixo; para dentro da base. A fita isolante é passada nas bordas, unindo as duas partes da garrafa e isolando o recipiente. Por último, é colocado água até um pouco mais da metade.

A foto 2 mostra o momento de confecção das armadilhas. 


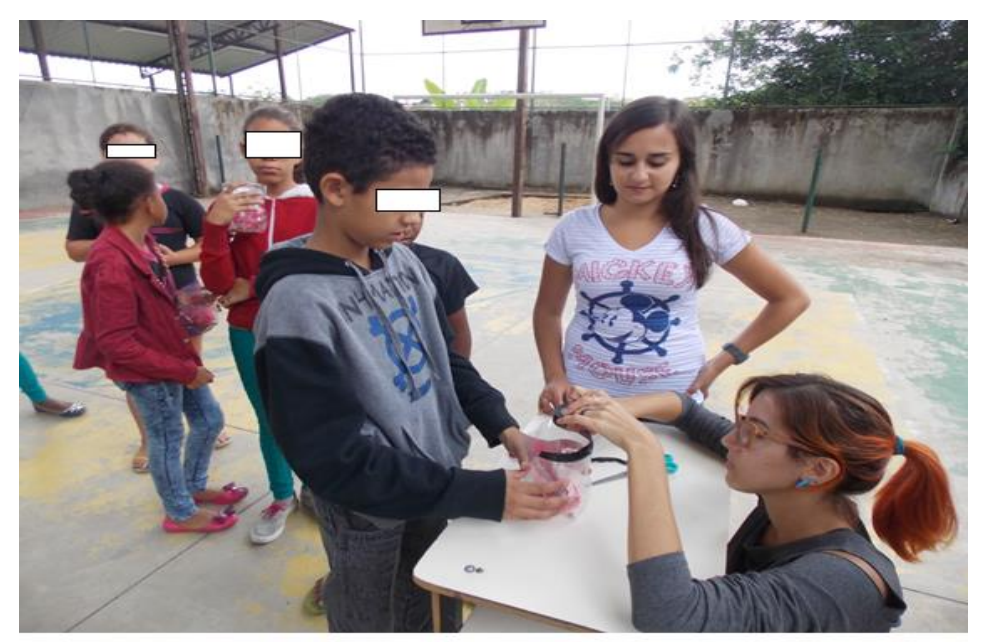

A importância das armadilhas se dá porque muitas vezes ao se realizar os procedimentos usuais de retirada da água parada o mosquito busca novos locais para sua reprodução, que podem não estar visíveis ou perceptíveis e que, portanto, torna difícil sua eliminação. Utilizando a armadilha, o mosquito realiza a desova na água parada, as larvas entram no recipiente através dos furos do tecido à procura de alimento e ali ficam presas à medida que vão crescendo e acabam morrendo. É uma alternativa mais eficaz do que as tradicionais no combate ao mosquito.

\subsubsection{Repelente caseiro}

Foi feita a demonstração de uma receita de repelente caseiro aos alunos. Como parte do processo demora 4 dias, o repelente foi feito em casa pelos bolsistas e distribuído pronto aos alunos em frascos de amostra individuais. Os materiais utilizados e suas respectivas quantidades estão descritos na tabela 1 . A receita foi retirada do site www.tuasaude.com.

Tabela 1 - Materiais usados para a confecção do repelente

\begin{tabular}{|c|c|}
\hline Materiais & Quantidade \\
\hline Álcool & $500 \mathrm{~mL}$ \\
\hline Cravo da índia & $10 \mathrm{~g}$ \\
\hline Óleo mineral & $100 \mathrm{~mL}$ \\
\hline Recipiente & $1000 \mathrm{~mL}$ \\
\hline Frascos de 50 Ml & 12 unidades \\
\hline
\end{tabular}

Fonte: Acervo próprio 
Para fazer o repelente é necessário colocar o álcool e o cravo da índia em uma garrafa preferencialmente escura e agitar. $\mathrm{O}$ cravo da índia é deixado em infusão no álcool por quatro dias e é necessário agitar levemente a garrafa duas vezes ao dia. Ao fim dos quatro dias, retira-se o cravo da índia e coloca-se o óleo, que tem a função de facilitar a aderência do repelente à pele.

A eficácia do repelente caseiro está ligada ao aroma do cravo, que é desagradável para o mosquito. Por ser feito sem a adição de substâncias que podem ser prejudiciais à saúde (como o DEET e a Icaridina), ele não possui restrições de uso, podendo, inclusive, ser usado por gestantes e crianças.

\subsubsection{Atividades lúdicas sobre a dengue}

No dia 04 de março, as atividades foram feitas com os alunos do $1^{\circ}$ e $2^{\circ}$ período da Educação Infantil, com faixa etária entre 4 e 5 anos de idade.

Foram confeccionadas máscaras representativas do mosquito Aedes aegypti (Foto 3) e foram distribuídas folhas com desenhos para colorir que ilustravam os sintomas da dengue. Pela idade das crianças, considerou-se mais interessante essa abordagem da identificação da doença, para que levassem o aprendizado para casa e pudessem conscientizar também os pais.

\section{Foto 3 - Alunos após a decoração das máscaras temáticas \\ Fonte: Acervo próprio}

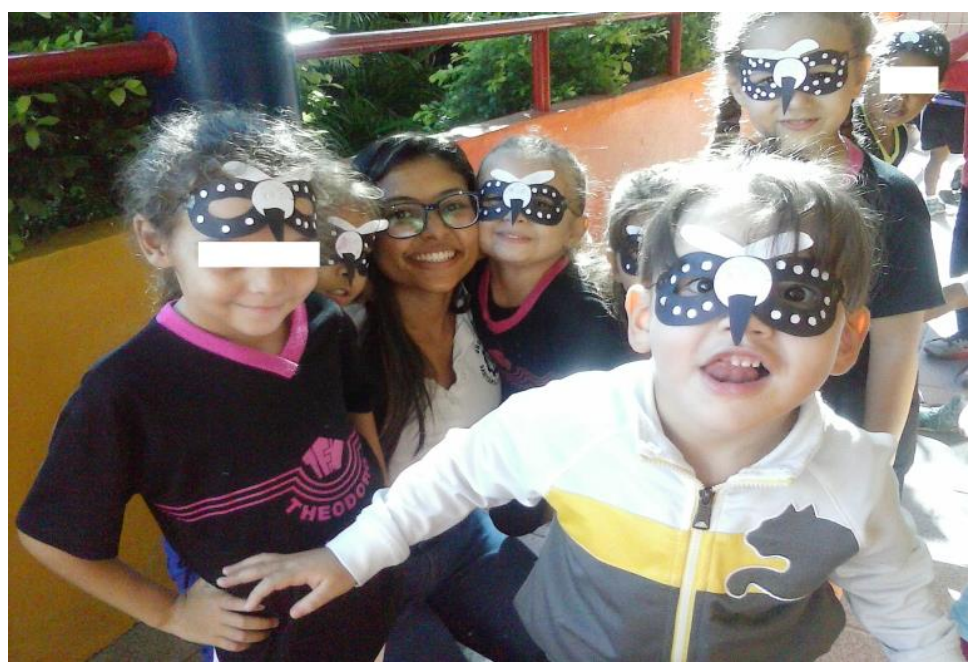

\subsection{Atividade sobre o Dia do Livro}

Com objetivo de incentivar a leitura e a criatividade, foi realizada com alunos de 4 a 6 anos uma oficina de leitura. Foram escolhidos previamente alguns livros da literatura infantil produzidos na cidade para serem trabalhados com os alunos. 
Uma vez que as crianças não haviam concluído o processo de alfabetização, foram feitos grupos para contação de histórias por parte dos bolsistas. Após a leitura dos livros, as crianças foram incentivadas a fazerem desenhos que ilustrassem as histórias lidas para eles.

\subsection{Atividade sobre o Dia do Trabalho}

Em comemoração ao Dia do Trabalho, foi realizada uma feira de profissões. Para isso, foram convidados alunos de graduação de diferentes cursos da Universidade Federal de Juiz de Fora. Foram convidados também o Corpo de Bombeiros de Juiz de Fora e Polícia Militar de Minas Gerais. Nessa ocasião, os alunos tiveram a oportunidade de conhecer um pouco de cada área.

\subsection{Atividade sobre o Dia do Meio Ambiente}

Em virtude da comemoração do Dia do Meio Ambiente, propôs-se a fabricação de tinta ecológica pelos alunos. Essa atividade foi desenvolvida com os alunos do $4^{\circ}$ ano do Ensino Fundamental e teve como principal objetivo mostrar que é possível viver harmonicamente com o Meio Ambiente, aproveitando de seus recursos naturais de forma consciente, sem que haja malefício ao mesmo.

Para a produção de tinta ecológica são necessárias apenas água, cola e terra. As proporções estão apresentadas na tabela 2.

Tabela 2 - Materiais usados para a confecção da tinta ecológica

\begin{tabular}{|l|l|}
\hline \multicolumn{1}{|c|}{ Materiais } & \multicolumn{1}{c|}{ Quantidade } \\
\hline Água & $1 \mathrm{Litro}$ \\
\hline Cola Branca & $10 \mathrm{~kg}$ \\
\hline Terra Argilosa & 6 a $8 \mathrm{~kg}$ \\
\hline
\end{tabular}

Fonte: Acervo próprio

Antes de misturar todos os ingredientes é necessário que se peneire a argila de forma que os grãos sejam os mais finos possíveis. Depois de peneirada, acrescentar os demais ingredientes. Nesse ponto, a tinta já está formada. Porém, para a tinta ficar ainda mais fina é necessário passá-la pela peneira por várias vezes, de forma que quanto maior o número de vezes de passadas pela peneira, mais fina fica a tinta. 
Para que a tinta adquira coloração, recomenda-se o uso de argila branca e agentes pigmentadores. Na escola, ensinou-se as crianças a macerar folhas para conseguir pigmentações verdes e flores para outras pigmentações, sendo que a pigmentação será dada de acordo com a pétala das flores utilizadas. A tinta foi produzida em menor proporção e foi posteriormente usada para a confecção de quadros que foram dispostos na feira cultural realizada em uma das escolas.

\subsection{Workshop de Educação Ambiental}

Tendo em mente a necessidade atual de se reutilizar materiais que, normalmente, seriam descartados como lixo, foi realizada essa atividade, que contou com palestras e uma oficina de fabricação de brinquedos, que foram parcialmente produzidos com materiais usados, tais como garrafas PET e palitos de picolé.

A oficina foi oferecida aos professores das escolas em questão, com o objetivo de gerar conhecimentos e transmiti-los, posteriormente, aos alunos.

\subsection{Atividade sobre o Dia Mundial de Combate à AIDS}

Sabendo da dificuldade de se trabalhar com temáticas relacionadas a sexo e sexualidade com crianças e adolescente, aproveitou-se o Dia Mundial de Combate e AIDS, para a realização de um dia de palestra sobre Doenças Sexualmente Transmissíveis. Esse trabalho desenvolvido com os alunos do $5^{\circ}$ ano do Ensino Fundamental, atendeu crianças e adolescentes entre 10 e 15 anos, visto que o índice de repetência nesse período é grande nas escolas.

$\mathrm{Na}$ palestra, explicou-se um pouco sobre como contrair cada uma dessas doenças, como elas se manifestam, sua prevenção e seu tratamento. As doenças retratadas foram cancro mole, hepatites virais, herpes genital, gonorreia e infecção por clamídia, Papilomas Vírus Humano (HPV), tricomoníase, AIDS, entre outras.

Os alunos pareceram muito interessados na palestra, mostrando que tocar em assuntos que envolvem sexo e sexualidade é importante para eles, apesar de serem considerados ainda muito jovens para conversar sobre o assunto.

\section{CONSIDERAÇÕES FINAIS}

De acordo com o artigo segundo da lei 9.795 de 1999, que institui a Política Nacional da Educação Ambiental, "a educação ambiental é um componente essencial e permanente da educação nacional, devendo estar presente, de forma articulada, em todos os níveis e modalidades do processo educativo, em caráter formal e não-formal”. 
Nesse sentido foi possível perceber a importância da interação entre os bolsistas, os alunos e os professores, de modo a construir o projeto em cima dos interesses da escola e sem prejudicar suas atividades regulares, fortalecendo assim todo o trabalho desenvolvido.

Os eventos estabelecidos constituem ações simples, mas o diálogo entre a universidade e a escola trouxe grande motivação aos envolvidos e uma enorme receptividade. Se por um lado é permitido aos bolsistas aplicar os conhecimentos adquiridos em sala de aula, por outro é proporcionado aos alunos um momento em que podem se expressar, construir valores e adquirir conhecimentos complementares às disciplinas regulares.

Há uma rotatividade na escolha das turmas contempladas, tornando o contato entre os bolsistas e os alunos mais individual e rico. Assim, cada trabalho é adequado à faixa etária da turma contemplada, salvo as atividades em que a escola toda é convidada a participar

\section{REFERÊNCIAS BIBLIOGRÁFICAS}

Brasil. Lei $\mathrm{n}^{\mathrm{o}}$ 9.795, de 27 de abril de 1999. Dispõe sobre a educação ambiental, institui a Política Nacional de Educação Ambiental e dá outras providências. Presidência da República, Brasília, DF, 27 de abril de 1999.

Repelente caseiro afasta o mosquito da Dengue, Zika e Chikungunya. Disponível em: <http://www.tuasaude.com/repelente-caseiro/> Acesso em: 22 mar 2016.

Boletim Epidemiológico - Volume 47 - n 16 - 2016 - Monitoramento dos casos de dengue, febre de chikungunya e febre pelo vírus Zika até a Semana Epidemiológica 9, 2016 - link para acesso: http://portalsaude.saude.gov.br/images/pdf/2016/abril/11/2015013---Dengue-SE9.pdf

BRASIL. Parâmetros Curriculares Nacionais. Brasília, MEC/SEF, vols. 8 e 10, 1997. SERRÃO, Margarida; BALEEIRO, Maria Clarice. Aprendendo a ser e a conviver. 2 ed. São Paulo: FTD, 1999. 